\title{
Use of Grape Peels By-Product for Wheat Pasta Manufacturing
}

\author{
Mădălina Iuga *(D) and Silvia Mironeasa *(D) \\ Faculty of Food Engineering, Ştefan cel Mare University of Suceava, 13 Universitatii Street, \\ 720229 Suceava, Romania \\ * Correspondence: madalina.iuga@usm.ro (M.I.); silviam@fia.usv.ro (S.M.)
}

check for

updates

Citation: Iuga, M.; Mironeasa, S. Use of Grape Peels By-Product for Wheat Pasta Manufacturing. Plants 2021, 10, 926. https://doi.org/10.3390/ plants10050926

Academic Editor: Ivo Vaz de Oliveira

Received: 4 April 2021

Accepted: 4 May 2021

Published: 6 May 2021

Publisher's Note: MDPI stays neutral with regard to jurisdictional claims in published maps and institutional affiliations.

Copyright: (c) 2021 by the authors. Licensee MDPI, Basel, Switzerland. This article is an open access article distributed under the terms and conditions of the Creative Commons Attribution (CC BY) license (https:// creativecommons.org/licenses/by/ $4.0 /)$.

\begin{abstract}
Grape peels (GP) use in pasta formulation represents an economic and eco-friendly way to create value-added products with multiple nutritional benefits. This study aimed to evaluate the effect of the GP by-product on common wheat flour (Triticum aestivum), dough and pasta properties in order to achieve the optimal level that can be incorporated. Response surface methodology (RSM) was performed taking into account the influence of GP level on flour viscosity, dough cohesiveness and complex modulus, pasta color, fracturability, chewiness, cooking loss, total polyphenols, dietary fibers and resistant starch amounts. The result show that $4.62 \%$ GP can be added to wheat flour to obtain higher total polyphenols, resistant starch and dietary fiber contents with minimum negative effects on pasta quality. Flour viscosity, dough cohesiveness, complex modulus and pasta fracturability of the optimal sample were higher compared to the control, while chewiness was lower. Proteins' secondary structures were influenced by GP addition, while starch was not affected. Smooth starch grains embedded in a compact protein structure containing GP fiber was observed. These results show that GP can be successfully incorporated in wheat pasta, offering nutritional benefits by their antioxidants and fiber contents, without many negative effects on the final product's properties.
\end{abstract}

Keywords: grape peels; pasta; wheat flour; fibers; antioxidants

\section{Introduction}

Nowadays, consumer behavior is changing and functional foods with significant health benefits are gaining increasing attention. The food industry generates high amounts of by-products that may be considered an opportunity for a sustainable valorization in order to minimize the waste impact and to ensure environmental protection. Winery by-products' conversion into value-added products is of high interest for producers, consumers and researchers. One method of valorization is the inclusion of byproducts in food products in order to increase their nutritional value. Pasta is consumed worldwide and can be considered a good matrix for bioactive compounds' incorporation [1].

About $50 \%$ of the grape pomace is composed of grape peels (GP), depending on the grape variety and pedo-climatic conditions [2,3]. Some health problems such as cardiovascular diseases, stroke and some cancer types can be prevented by an adequate intake of fruits and vegetables due to their high amounts of bioactive compounds [4]. GP are a source of polyphenolic compounds and dietary fiber [5-7], components that can exert antioxidant an antimicrobial action [8,9]. The most important GP components with antioxidant characters are anthocyanins, hydroxycinnamic acids, catechins and flavonols, which can determine the inhibition of oxidative processes of low-density lipoproteins $[10,11]$.

The potential applications of polyphenols and dietary fiber to preserve foods and prolong their shelf-life were demonstrated in some previous studies [12,13]. GP contain up to $60 \%(\mathrm{dm})$ dietary fiber, the insoluble fraction prevailing, followed by sugars, which can total up to $70 \%$, depending on the vinery process applied $[10,14]$. Due to the essential role played by dietary fiber for human health, such as improvement of gastrointestinal activity, reducing glycemic responses and cholesterol levels in the blood [13], it is necessary to take 
alternative sources of dietary fiber to achieve the recommended consumption, which is about 25-30 g per day [1].

There are some studies revealing the possibility to create value-added products by incorporating grape by-products in bakery products or pasta [15-18]. Grape by-products can be used as semolina replacer in pasta with many positive effects on the technological properties, such as firmness and adhesiveness, but also on the physico-chemical and functional characteristics of the final product, such as increased total polyphenolics content and antioxidant activity, and lowering of the glycaemic index trough resistant starch content increase [1]. Simonato et al. [19] studied the effects of Moringa oleifera leaf powder on wheat fresh pasta and observed an increase of cooking loss and a reduced firmness along with nutritional value enhancement given by higher phenols and mineral contents. The addition of coconut by-products to wheat pasta led to lower firmness and color changes, while the fiber, protein and lipid contents increased [20]. Sobota et al. [21] underlined the possibility to increase durum wheat pasta fiber content by incorporating different vegetables powders (beet, carrot, kale), along with significant changes of color. According to the results presented by $\mathrm{Xu}$ et al. [22], the incorporation of apple pomace in noodles caused a cohesiveness and tensile strength reduction and cooking loss increase, with the hardness and adhesiveness of the noodles not being changed, while gumminess, chewiness, and springiness recorded differences. Fortification of durum wheat pasta with onion skin by-products resulted in increased dietary fiber, ash, total phenolic compounds, flavonoids content and antioxidant activity, while cooking loss, water solubility index and redness were higher and the optimal cooking time lower [23]. Zarzycki et al. [24] showed that the addition of Moldavian dragonhead seeds residue in pasta resulted in higher nutritional value by increasing proteins, dietary fiber and mineral contents, without negative effects on the cooking and sensory characteristics of the pasta. Another study made by Simonato et al. [25] underlined the opportunity to increase total polyphenol contents and antioxidant capacity of pasta by supplementation with olive pomace. The authors found a decrease of rapidly digestible starch and an increase of slowly digestible starch, resistant starch, swelling index, water absorption, cooking loss and pasta firmness [25].

The addition of fiber-rich ingredients can have significant effects on dough rheological properties and on the final product texture, microstructure and color. The effects of grape by-products on the composite flour and final product properties are proportional to the addition level [3]. Mironeasa et al. [16] revealed some negative effects of GP on dough rheology caused by gluten dilution, which can be minimized by particle size reduction. Food texture, volume and color are strongly affected by high levels of grape by-products, Gaita et al. [17] suggesting that amounts up to 6\% GP can be incorporated into pasta containing eggs without significant negative effects on the sensory acceptance. On the other hand, fortification of bakery and pasta products with grape by-products led to a nutritional value increase due to the intake of fiber and polyphenolics with antioxidant activity $[4,5,15]$. Grape peels' phenolics, such as phenolic acids, tannins and flavonoids, could have reducing effects on starch digestibility due to their abilities to inhibit enzyme activity or by the formation of starch-polyphenol complexes with resistance to enzyme attacks [26]. Furthermore, polyphenols can slow down starch gelatinization via the interaction through hydrogen bonds with amylose molecules [27]. Saad et al. [28] found that wheat pasta dough rheological properties in terms of extensibility and water absorption increased, while elasticity decreased, when cucumber pomace was added. The mineral and polyphenols content of noodles were improved, while a reduction of protein and carbohydrate contents was observed [28].

In countries where durum wheat is not widely cultivated, common wheat usually represents the basic ingredient for pasta production. There are some studies revealing the possibility to use fiber and polyphenols-rich ingredients in pasta formulation, but to our knowledge, there are no studies revealing the effects of GP on common white wheat flour for pasta production. The approach of this study is complex, evidencing the technological, nutritional, molecular and structural changes of flour, dough and pasta. The knowledge of 
the interactions of grape peels with other biopolymers from wheat is very important for the development of novel pasta products. Thus, the aim of this study was to underline the impact of GP components on white wheat flour (WWF), dough and pasta properties, and to optimize the addition level in order to obtain the best product quality. Furthermore, a characterization of the optimum and control products was made.

\section{Results}

\subsection{Diagnostic Checking of the Models}

The ANOVA results for the model fitting presented in Table 1 show that all of the mathematic models chosen were significant and predicted accurately the responses, the $F$-value being significant $(p<0.01)$ in all cases and $R^{2}$ values being more than 0.76 .

Table 1. ANOVA results for the fitted models for different characteristics of flour, dough and pasta.

\begin{tabular}{cccccc}
\hline Response & Model & $\boldsymbol{F}$-Value & $\boldsymbol{p}$-Value & $\boldsymbol{R}^{\mathbf{2}}$ & Adj. $^{-\boldsymbol{R}^{\mathbf{2}}}$ \\
\hline$\eta_{\max }(\mathrm{Pa} \cdot \mathrm{s})$ & quadratic & 36.23 & $<0.01$ & 0.83 & 0.81 \\
$\mathrm{G}^{*}(\mathrm{~Pa})$ & quartic & 31.27 & $<0.01$ & 0.91 & 0.88 \\
$\mathrm{Co}$ & quadratic & 24.14 & $<0.01$ & 0.76 & 0.73 \\
$\mathrm{C}^{*}$ & quartic & 32.72 & $<0.01$ & 0.91 & 0.88 \\
$\mathrm{~F}(\mathrm{~g})$ & quartic & 179.30 & $<0.01$ & 0.98 & 0.98 \\
$\mathrm{Ch}(\mathrm{J})$ & quadratic & 26.38 & $<0.01$ & 0.78 & 0.75 \\
$\mathrm{CL}(\%)$ & quartic & 91.58 & $<0.01$ & 0.97 & 0.96 \\
$\mathrm{RS}(\%)$ & cubic & 181.00 & $<0.01$ & 0.98 & 0.97 \\
$\mathrm{TPC}(\mu \mathrm{g}$ GAE/g) & quartic & 85.84 & $<0.01$ & 0.96 & 0.95 \\
$\mathrm{TDF}(\%)$ & fifth & 1503.06 & $<0.01$ & 0.99 & 0.99 \\
\hline
\end{tabular}

$\eta_{\max }$-peak viscosity, $\mathrm{G}^{*}$-complex modulus, Co-cohesiveness, $\mathrm{C}^{*}$-chroma, F-fracturability, Ch-chewiness, $\mathrm{CL}$ - cooking loss, RS—resistant starch, TPC—-total polyphenols content, TDF-total dietary fiber.

Flour peak viscosity $\left(\eta_{\max }\right)$, dough cohesiveness $(\mathrm{Co})$ and boiled pasta chewiness $(\mathrm{Ch})$ data were fitted to the quadratic model, which described $83 \%, 76 \%$ and $78 \%$ of the data variation, respectively. Dough complex modulus $\left(\mathrm{G}^{*}\right)$, dry pasta chroma $\left(\mathrm{C}^{*}\right)$, fracturability $(\mathrm{F})$, cooking loss (CL) and polyphenolic content (TPC) results were fitted to the quartic model, with $91 \%, 91 \%, 98 \%, 97 \%$ and $96 \%$, respectively, of the data variation being explained. The cubic model explained $98 \%$ of data variation for resistant starch content (RS), while the results for the dietary fiber content (TDF) were fitted to the fifth model, which explained $99 \%$ of the variation.

\subsection{Effects of GP on Flour and Pasta Characteristics}

A Supplementary Materials section containing the graphics for the variation of the responses with GP level is provided.

Peak viscosity increased with GP level increase (Figure S1), the biggest significant $(p<0.01)$ positive influence being obtained for the linear term Equation $(1)$.

$$
\eta_{\max }(\mathrm{Pa} \cdot \mathrm{s})=0.42+0.14 \mathrm{~A}^{* *}-0.01 \mathrm{~A}^{2}
$$

where $\eta_{\max }$ - peak viscosity, A-GP level, ${ }^{* *}$ significant at $p<0.01$.

An increase of $G^{*}$ as the GP level was higher was observed (Figure S2a), the linear and quadratic terms having significant influence $(p<0.05)$ on the response Equation $(2)$.

$$
\mathrm{G}^{*}(\mathrm{~Pa})=96083.29+23997.76 \mathrm{~A}^{* *}+38352.65 \mathrm{~A}^{2 *}+808.26 \mathrm{~A}^{3}-27020.94 \mathrm{~A}^{4}
$$

where $\mathrm{G}^{*}$ - complex modulus, A-GP level, ${ }^{* *}$ significant at $p<0.01,{ }^{*}$ significant at $p<0.05$.

More cohesive dough was obtained as the GP addition level was higher (Figure S2b), the linear term having the greatest significant $(p<0.01)$ influence Equation (3). The negative effects of GP, which are a fiber-rich ingredient, were minimized because small particle size $(<180 \mu \mathrm{m})$ was used.

$$
\mathrm{Co}=0.40+0.02 \mathrm{~A}^{* *}+0.01 \mathrm{~A}^{2}
$$


where Co-cohesiveness, A-GP level, ${ }^{* *}$ significant at $p<0.01$.

Pasta color was affected by GP incorporation, a significant $(p<0.01)$ decrease of $C^{*}$ being observed with the addition level increase (Figure S3a). The biggest negative influence was obtained for the linear term of the factor Equation (4).

$$
\mathrm{C}^{*}=23.08-2.72 \mathrm{~A}^{* *}+1.42 \mathrm{~A}^{2}-0.35 \mathrm{~A}^{3}+0.03 \mathrm{~A}^{4}
$$

where $C^{*}$-chroma, A-GP level, ** significant at $p<0.01$.

Dry pasta fracturability expressed as the maximum force needed to break the sample can be an indicator of pasta resistance to transport and manipulation. The addition of GP caused an increase of $\mathrm{F}$ with the level increase (Figure S3b). The linear and cubic terms presented significant positive influence $(p<0.05)$, while the quadratic term had a negative effect on the response Equation (5).

$$
\mathrm{F}(\mathrm{g})=3158.72+1837.63 \mathrm{~A}^{* *}-1052.11 \mathrm{~A}^{2 * *}+256.32 \mathrm{~A}^{3 *}-19.84 \mathrm{~A}^{4 *}
$$

where F-fracturability, A-GP level, ${ }^{* *}$ significant at $p<0.01,{ }^{*}$ significant at $p<0.05$.

GP addition caused a CL rise with the level increase (Figure S4a), the linear, quadratic and quartic terms presenting significant $(p<0.05)$ influences based on Equation (6). An acceptable cooking loss value should be less than $12 \%$ [5].

$$
\mathrm{CL}(\%)=0.66+6.33 \mathrm{~A}^{* *}-3.02 \mathrm{~A}^{2 *}+0.61 \mathrm{~A}^{3}-0.04 \mathrm{~A}^{4 *}
$$

where CL-cooking loss, A-GP level, ${ }^{* *}$ significant at $p<0.01,{ }^{*}$ significant at $p<0.05$.

Pasta chewiness is expressed as the energy required to chop the sample until it is ready to swallow [29]. GP level increase caused a proportional decrease of pasta chewiness (Figure S4b), the highest influence being observed for the linear term Equation (7).

$$
\mathrm{Ch}=3696.18-287.20 \mathrm{~A}^{* *}+79.49 \mathrm{~A}^{2}
$$

where $\mathrm{Ch}$-chewiness, A-GP level, ${ }^{* *}$ significant at $p<0.01$.

Resistant starch content was significantly influenced $(p<0.01)$ by the linear, quadratic and cubic terms in Equation (8). A rise in RS with GP addition level increase was observed (Figure S5a).

$$
\operatorname{RS}(\%)=4.49+0.34 \mathrm{~A}^{* *}-0.43 \mathrm{~A}^{2 * *}+0.50 \mathrm{~A}^{3 * *}
$$

where RS-resistant starch content, A-GP level, ${ }^{* *}$ significant at $p<0.01$.

A significant positive influence $(p<0.01)$ was obtained for the linear term of GP level, while the quadratic and quartic terms exhibited a negative and significant $(p<0.05)$ effect on TPC response (Equation (9). TPC showed higher values with GP level increase (Figure S5b), as a result of polyphenols present in the added ingredient.

$$
\operatorname{TPC}(\%)=29.25+117.50 \mathrm{~A}^{* *}-55.362 \mathrm{~A}^{2 *}+11.17 \mathrm{~A}^{3}-0.77 \mathrm{~A}^{4 *}
$$

where TPC—-total polyphenols content, A-GP level, ** significant at $p<0.01, *$ significant at $p<0.05$.

GP are a rich source of soluble and insoluble dietary fibers, their incorporation in wheat pasta determining an increase of TDF with the level increase (Figure S5c). Significant positive influences $(p<0.01)$ were obtained for the linear, cubic and fifth terms, while the quadratic and quartic terms presented negative effects on the response (Equation (10)).

$$
\operatorname{TDF}(\%)=-4.58+9.17 \mathrm{~A}^{* *}-6.31 \mathrm{~A}^{2 * *}+2.01 \mathrm{~A}^{3 * *}-0.30 \mathrm{~A}^{4 * *}+0.02 \mathrm{~A}^{5 * *}
$$

where TDF-total dietary fiber content, A-GP level, ${ }^{* *}$ significant at $p<0.01$. 


\subsection{Optimization of GP Level and Models Validation}

To obtain the maximum nutritional benefits with minimum quality characteristics' impairment, the optimization of GP level as a function of the considered responses showed that wheat flour can be supplemented with $4.62 \%$ GP (Table 2), with a desirability of 0.57 .

Table 2. Confirmation of the optimized parameters and control sample characteristics.

\begin{tabular}{|c|c|c|c|c|}
\hline \multirow{2}{*}{ Parameter } & \multicolumn{3}{|c|}{ OGP } & \multirow{2}{*}{ Control } \\
\hline & Predicted Value & Experimental Value & Relative Deviation * (\%) & \\
\hline A-GP (\%) & $4.62 \pm 0.00$ & $4.62 \pm 0.00$ & - & - \\
\hline$\eta_{\max }(\mathrm{Pa} \cdot \mathrm{s})$ & $0.83 \pm 0.06^{x}$ & $0.85 \pm 0.06^{\mathrm{xa}}$ & 2.35 & $0.42 \pm 0.02^{b}$ \\
\hline $\mathrm{G}^{*}(\mathrm{~Pa})$ & $113,595.55 \pm 6604.45^{x}$ & $113,733.33 \pm 950.44^{\text {ха }}$ & 0.12 & $51,170.00 \pm 1822.44^{b}$ \\
\hline Co & $0.41 \pm 0.01^{\mathrm{x}}$ & $0.41 \pm 0.01$ ха & 0.00 & $0.36 \pm 0.01^{b}$ \\
\hline$C^{*}$ & $19.07 \pm 0.40^{x}$ & $19.26 \pm 0.06$ ya & 0.99 & $21.89 \pm 0.06^{b}$ \\
\hline $\mathrm{F}(\mathrm{g})$ & $5432.15 \pm 106.15^{x}$ & $5659.67 \pm 159.22$ ха & 4.02 & $4207.33 \pm 123.18^{b}$ \\
\hline $\mathrm{Ch}(\mathrm{J})$ & $3583.12 \pm 116.08^{x}$ & $3353.11 \pm 162.77$ ха & -6.86 & $4910.27 \pm 72.29^{b}$ \\
\hline CL $(\%)$ & $6.81 \pm 0.25^{x}$ & $7.03 \pm 0.24^{\mathrm{xa}}$ & 3.13 & $5.53 \pm 0.19^{b}$ \\
\hline RS (\%) & $4.60 \pm 0.10^{x}$ & $4.79 \pm 0.01$ ya & 3.97 & $2.58 \pm 0.10^{b}$ \\
\hline TPC ( $\mu \mathrm{g}$ GAE/g) & $141.48 \pm 4.21^{\mathrm{x}}$ & $144.99 \pm 2.78^{\text {ха }}$ & 2.42 & $106.75 \pm 4.18^{b}$ \\
\hline TDF $(\%)$ & $1.43 \pm 0.03^{x}$ & $1.38 \pm 0.03^{\mathrm{xa}}$ & -3.62 & $0.02 \pm 0.00^{b}$ \\
\hline
\end{tabular}

OGP-optimal formulation of wheat flour with grape peels, A-GP (grape peels) level, $\eta_{\max }$-peak viscosity, $\mathrm{G}^{*}$-complex modulus, Co-cohesiveness, $C^{*}$ - chroma, F-fracturability, Ch-chewiness, CL-cooking loss, RS-resistant starch, TPC—total polyphenols content, TDF-total dietary fiber, means in the same row followed by different letters ( $x-y$ for differences among predicted and observed values, $\mathrm{a}-\mathrm{b}$ for differences between OGP and control) are significantly different $(p<0.05),{ }^{*}$ relative deviation $=[($ experimental value - predicted value)/experimental value] $\times 100$.

For the model's validation, a pasta sample was made using the optimal level of GP that resulted after optimization. The responses were checked in triplicate and the experimental values were less than $5 \%$ different from the predicted ones (Table 2), except for chewiness, which was lower by $6.86 \%$ than the predicted value. Compared to the control, significantly $(p<0.01)$ higher $\mathrm{G}^{*}, \eta_{\max }$, dough Co, F, CL, RS, TPC and TDF contents were obtained, while $C^{*}$ and boiled pasta $C h$ were smaller (Table 2). Consequently, the nutritional and functional values of the optimized pasta were enhanced compared to the control and the quality parameters were kept. Even if higher CL was obtained (6.81\%), the value was less than $12 \%$, the limit recommended for acceptable pasta. The OGP sample presented a more cohesive, elastic and viscous dough, which was probably related to the higher resistance to break (F) of pasta, which was desirable.

\subsection{Determination of Control and Optimal Product Properties}

\subsubsection{FTIR Analysis of Flours}

FTIR analysis allowed the identification of changes in bonding and possible interactions between composite flour components, underlying the impact of GP addition to WWF. The representative spectra of OGP and control samples is presented in Figure 1 and shows the peaks of the functional groups and the vibration ways of the compounds. Several peaks were identified in the analyzed spectra $\left(650-4000 \mathrm{~cm}^{-1}\right)$ and were attributed to the molecular linkages of some chemical components such as starch, proteins and polyphenols.

The deconvoluted spectra in the range of $800-1300 \mathrm{~cm}^{-1}$ (Figure 1b1) showed the characteristics of starch grains. The amount of hydrated starch structures was identified at $995 \mathrm{~cm}^{-1}$, the amorphous starch at $1022 \mathrm{~cm}^{-1}$ and the short-ordered starch structures at $1047 \mathrm{~cm}^{-1}$ [30]. No significant changes $(p>0.05)$ were observed in starch structure between OGP and control samples (Table 3). The intermolecular associations were identified at $1613-1620 \mathrm{~cm}^{-1}$, the intramolecular associations at $1627-1635 \mathrm{~cm}^{-1}, \beta$-sheets structures at $1620-1644 \mathrm{~cm}^{-1}, \alpha$-helix at $1650-1660 \mathrm{~cm}^{-1}$ and $\beta$-turn at $1660-1680 \mathrm{~cm}^{-1}[31,32]$. The OGP sample presented higher inter- and intra-molecular associations compared to the control, which lacked absorbance for intramolecular associations. Significant lower $(p<0.01)$ $\alpha$-helix conformations were identified for OGP compared to the control, while $\beta$-turn and 
antiparallel $\beta$-sheets structures were higher (Table 3). The presence of fibers could be observed from the peaks at 1149 and $1077 \mathrm{~cm}^{-1}$ [30], while the phenolic compounds could be identified at 1609-1608 and 1519-1516 $\mathrm{cm}^{-1}$ [33] (Figure 1b2) and $1747 \mathrm{~cm}^{-1}$.

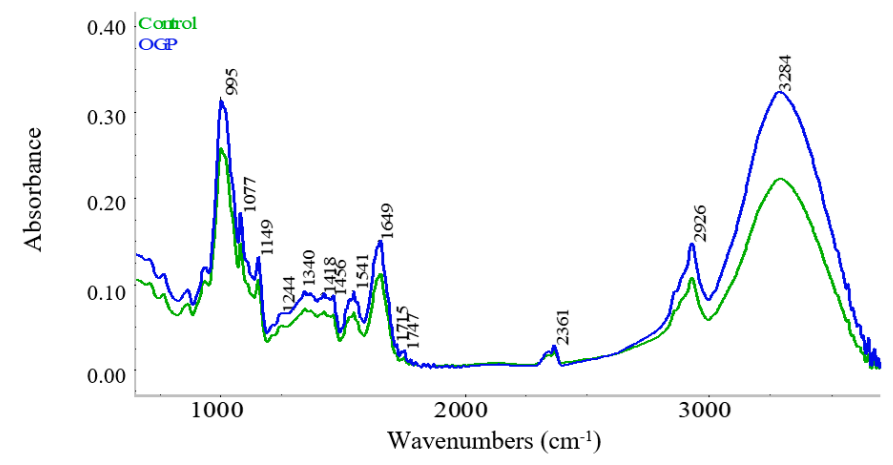

(a)

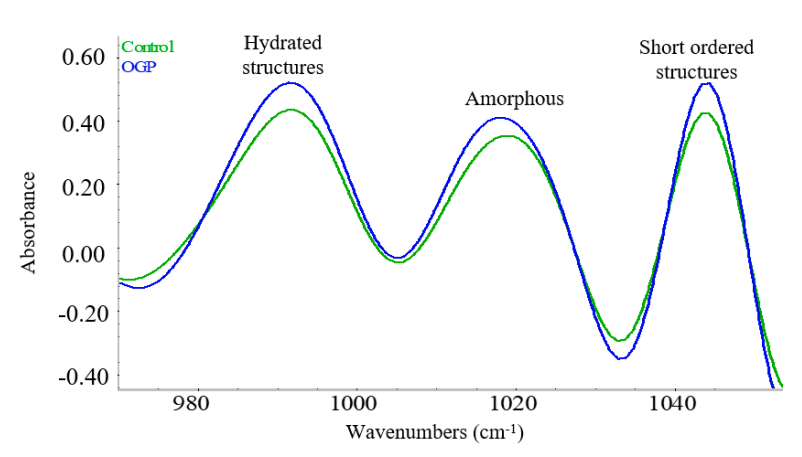

(b1)

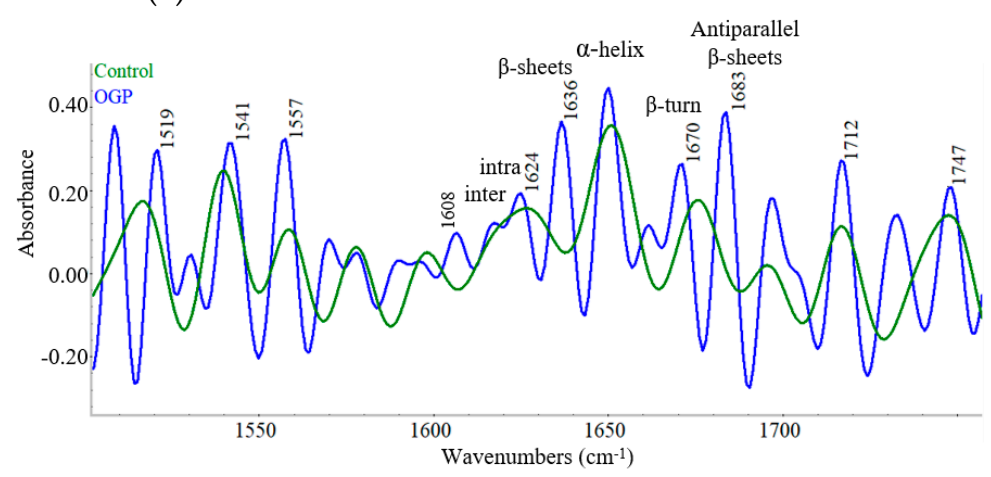

(b2)

Figure 1. (a) Average spectra of optimal wheat-grape peels (OGP) and control samples in mid-infrared region; (b1) starch components' deconvoluted spectra; (b2) protein and polyphenol components' deconvoluted spectra.

Table 3. Optimal and control product properties.

\begin{tabular}{ccc}
\hline Parameter & OGP & Control \\
\hline Intermolecular associations (\%) & $1.71 \pm 0.09^{\mathrm{a}}$ & $0.00 \pm 0.00^{\mathrm{b}}$ \\
Intramolecular associations (\%) & $4.75 \pm 0.05^{\mathrm{a}}$ & $0.00 \pm 0.00^{\mathrm{b}}$ \\
$\beta$-sheets (\%) & $13.17 \pm 0.44^{\mathrm{a}}$ & $13.23 \pm 0.58^{\mathrm{a}}$ \\
$\alpha$-helix (\%) & $17.25 \pm 0.71^{\mathrm{a}}$ & $26.67 \pm 1.89^{\mathrm{b}}$ \\
$\beta$-turn (\%) & $13.22 \pm 0.39^{\mathrm{a}}$ & $2.23 \pm 0.59^{\mathrm{b}}$ \\
Antiparallel $\beta$-sheets (\%) & $19.74 \pm 0.93^{\mathrm{a}}$ & $5.44 \pm 0.85^{\mathrm{b}}$ \\
Hydrated crystallin starch structure (\%) & $32.16 \pm 0.37^{\mathrm{a}}$ & $34.66 \pm 1.90^{\mathrm{a}}$ \\
Short-ordered crystallin starch structure (\%) & $27.26 \pm 0.20^{\mathrm{a}}$ & $27.25 \pm 0.20^{\mathrm{a}}$ \\
Amorphous starch structure (\%) & $34.26 \pm 0.13^{\mathrm{a}}$ & $34.00 \pm 0.31^{\mathrm{a}}$ \\
Protein content (\% dm) & $14.29 \pm 0.10^{\mathrm{a}}$ & $13.93 \pm 0.09^{\mathrm{b}}$ \\
Lipid content (\% dm) & $0.21 \pm 0.02^{\mathrm{a}}$ & $0.13 \pm 0.02^{\mathrm{b}}$ \\
Ash (\% dm) & $0.80 \pm 0.08^{\mathrm{a}}$ & $0.63 \pm 0.01^{\mathrm{a}}$ \\
Carbohydrates (\% dm) & $83.07 \pm 0.22^{\mathrm{a}}$ & $85.28 \pm 0.11^{\mathrm{b}}$ \\
Radical scavenging activity (\%) & $38.74 \pm 1.14^{\mathrm{a}}$ & $20.15 \pm 0.26^{\mathrm{b}}$ \\
RDS (\% dm) & $54.38 \pm 0.24^{\mathrm{a}}$ & $69.78 \pm 0.69^{\mathrm{b}}$ \\
SDS (\% dm) & $19.61 \pm 0.95^{\mathrm{a}}$ & $17.35 \pm 0.20^{\mathrm{b}}$ \\
\hline
\end{tabular}

OGP—optimal formulation of wheat flour with grape peels, RDS—rapid digestible starch, SDS—-slowly digestible starch, dm-dry matter, a-b means in the same row followed by different letters are significantly different $(p<0.05)$. 


\subsubsection{Pasta Chemical Properties}

The chemical compositions of the OGP and control sample are presented in Table 3.

GP addition to wheat flour caused a significant $(p<0.01)$ increase of the protein, lipid, ash and carbohydrate contents (Table 3 ) of pasta. The OGP sample presented higher radical scavenging activity (38.74\%) compared to the control $(20.15 \%)$. On the other hand, cooked pasta RDS significantly decreased $(p<0.01)$ when GP was added, while SDS increased compared to the control.

\subsubsection{Microstructure Analysis}

Dry pasta microstructure analysis revealed a well-developed matrix comprised of a gluten network, which encompassed starch grains and fiber fractions (Figure 2). In both the control and OGP samples round and lenticular starch shapes with smooth surfaces were observed. The addition of GP resulted in a compact dough structure in which the proteins embedded the fine particles of fibers and starch grains.

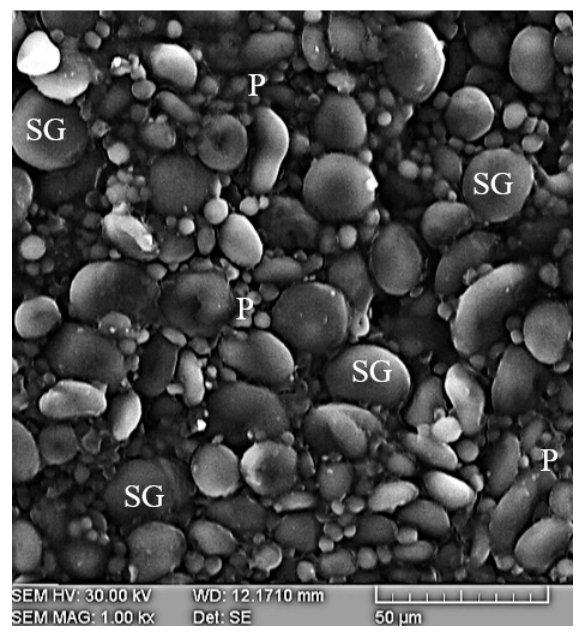

(a)

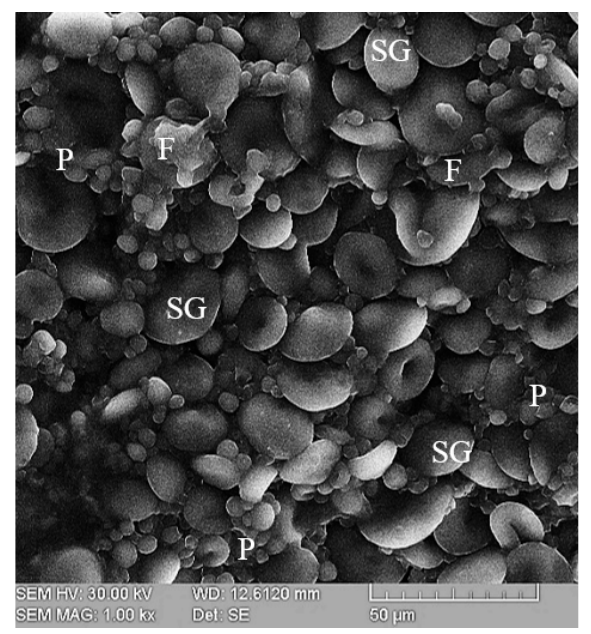

(b)

Figure 2. Dry pasta microstructure of (a) control and (b) optimal sample with grape peels (OGP): SG—starch grain; $\mathrm{P}$-protein matrix; F-fiber.

Dough ingredients influenced the pasta extrusion process, which resulted in surface structure changes. The addition of GP caused a slight increase of pasta surface roughness, as can be seen in Figure 3. OGP pasta presented an uneven surface compared to the control. The alternation of high and low regions was given by the use of the rigatoni mold.

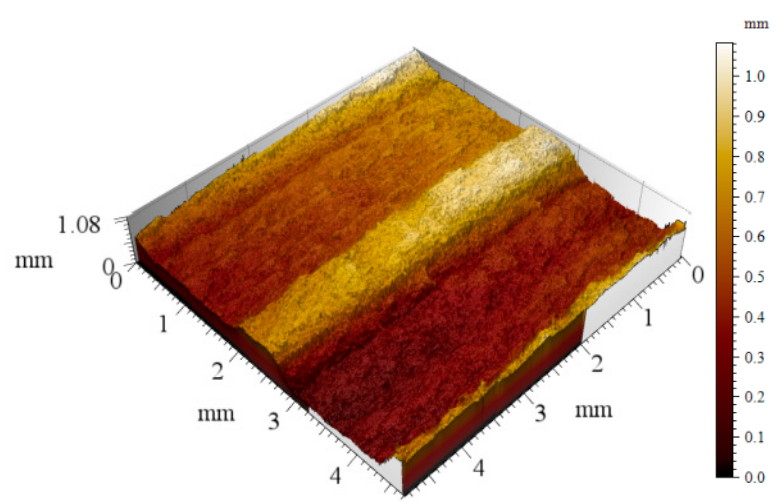

(a)

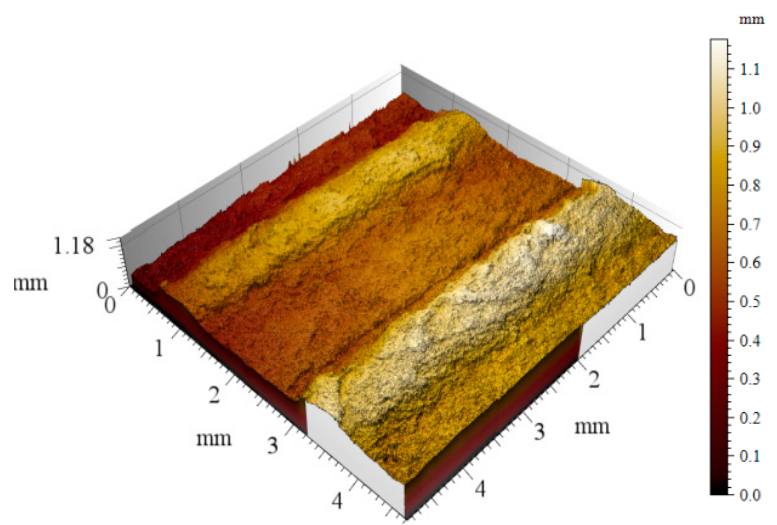

(b)

Figure 3. Three-dimensional dry pasta surface of (a) control and (b) optimal sample with grape peels (OGP). 


\section{Discussion}

\subsection{Effects of Grape Peels on Flour, Dough and Pasta Quality}

GP caused an increase of flour slurry peak viscosity, a similar trend being reported by Mironeasa et al. [34] for wheat flour supplemented with GP and can be related to the affinity of GP for water, which may determine a viscosity increase. Probably, the pectin content of GP can be another factor responsible for the viscosity increase since it may assist starch swelling [35]. Masoodi et al. [36] also reported a reduction of wheat flour peak viscosity when more than $5 \%$ apple pomace was incorporated.

The dynamic complex modulus' proportional increase with GP level could be explained by the strengthening effect of GP on the gluten network due to the presence of non-starch polysaccharides, tannins and polyphenols, which can form complexes with proteins [37]. Additionally, the oxidation of sulfhydryl groups to disulfides caused by the raised content of oxidizing compounds can possibly contribute to the complex modulus increase [3]. In this study, GP caused more cohesive dough. Mironeasa et al. [34] reported increased dough cohesiveness when small particle sizes of GP were used probably due to the ability of fine particles to better absorb water. GP fibers present many hydroxyl groups in their structure, which will determine higher interactions with water trough hydrogen bonds [38]. The sugars present in GP can also influence dough cohesiveness due to their water solubility [39]. Saad et al. [28] showed that pasta soft wheat dough supplemented with cucumber pomace rheological properties changed compared to the control, an increase of the extensibility and water absorption and a decrease of elasticity being observed.

Dry pasta chroma decreased as the amount of GP was higher. In the literature, Smith and $\mathrm{Yu}[40]$ reported higher $\mathrm{b}^{*}$ (yellow nuance) and lower $\mathrm{a}^{*}$ (red nuance) values of bread supplemented with grape pomace. High amounts of sugars found in GP can promote Maillard reactions and, along with the polyphenol's presence, may determine $C^{*}$ decrease. Additionally, the natural pigments from GP are responsible for color intensity decrease [41]. Other studies reveled that the addition of by-products such as dragonhead seeds, coconut residue or Moringa oleifera L. leaf [19,20,24] produced significant changes in pasta color, depending on the pigments present in the ingredient added. The quality of the final product depends on the chemical composition of the ingredient added, soluble dietary fibers such as inulin and fructooligosaccharides playing an important role in pasta network strength [42]. Polyphenol interactions with proteins can determine stronger dough structure [18,43], leading to higher fracturability values.

The higher cooking loss obtained in this study for pasta enriched with GP can be attributed to the polymer interactions in the gluten matrix and/or to the competition of proteins for water, leading to starch loss [44]. A similar trend of cooking loss was reported for fettuccini pasta supplemented with grape marc [5] and can be due to the dietary fiber content of the added ingredient. Xu et al. [22] reported also a proportional increase of pasta cooking loss with the addition level of apple pomace increase. Pasta texture can be a good predictor for consumer preferences. The results obtained showed a decreasing trend of pasta chewiness with GP level increase. The interference of GP components with starch, which led to a reduction of starch gelatinization during cooking, can be associated with lower chewiness [45]. The use of a small particle size $(<180 \mu \mathrm{m})$ for GP flour can be an advantage for pasta quality by diminishing the negative impact on the texture. A study regarding the influence of apple pomace on wheat pasta showed that this fortification caused a decrease of pasta chewiness as the level was higher [22], similar trend being reported also by Chen et al. [33] for pasta enriched with more than $1 \%$ grape seeds.

The nutritional value of wheat pasta was increased by the incorporation of GP. The raised resistant starch content of pasta enriched with GP can be attributed to the interactions between polyphenols and starch $[46,47]$ through non-covalent linkages formation. Furthermore, starch digestion diminution produced by the formation of linkages between polyphenols and starch can occur from the starch molecular structure modifications. A similar RS increase was reported by Simonato et al. [25] for pasta fortified with olive pomace. For instance, some studies revealed that these interactions can contribute to the 
ordered structure or development of starch crystallin areas, inducing RS formation [48,49]. On the other hand, the polyphenolics content of pasta increased with GP level increase. Gaita et al. [17] also reported higher polyphenolic contents for pasta supplemented with grape peels, the increase being directly proportional to the amount added. A study performed by Michalak-Majewska et al. [23] showed that the addition of onion skin powder caused an increase in total phenolic compounds, flavonoids content and antioxidant activity. The phenolic compounds present in grape by-products are highly accessible and available for metabolization in the human intestine [50]. In addition, the bioavailability polyphenols in pasta are directly related to the hydrogen, ionic, covalent, and hydrophobic interactions with proteins [3]. The addition of fiber-rich ingredients can be a useful technique to increase the nutritional value of the final product. Wheat pasta fiber content was enhanced by GP addition. Acun and Gül [51] also reported raised fiber content of cookies enhanced with seedless grape pomace. Similar to our study, Saad et al. [28] showed that the addition of cucumber pomace in soft wheat pasta induced the increase of fibers and polyphenol contents. Fibers are known to have some biological functions, such as activity against cancer, amelioration of gastrointestinal systems functioning, improvement of cardiovascular system activity, and decrease of cholesterol and glycaemia levels in blood [52]. Balli et al. [53] found that durum wheat tagliatelle with grape and olive pomace resulted in improved quality in terms of organoleptic and nutritional properties, with high levels of phenolic compounds and increased fibers content.

\subsection{Control and Optimal Product Properties}

In this study, the optimal amount of GP was found to be $4.62 \%$; at this level acceptable technological characteristics and superior nutritional value compared to the control were obtained. The optimal sample with GP (OGP) and the control made of wheat flour were characterized.

FTIR spectra showed the interactions between components of the composite flours. The peak at $3284 \mathrm{~cm}^{-1}$ was attributed to the $-\mathrm{OH}$ stretching vibrations, while the peak at $2926 \mathrm{~cm}^{-1}$ was assigned to the C-H stretching and showed higher absorbances for OGP probably due to the phenolic compound's presence [54]. The phenolic compounds found in GP have specific absorptions at $1712-1704 \mathrm{~cm}^{-1}$ corresponding to the carbonyl stretching and 1609-1608 and 1519-1516 $\mathrm{cm}^{-1}$ given by the stretching vibrations of $\mathrm{C}=\mathrm{C}$ [55] (Figure 1b2). The galloyl group's presence could possibly be observed at about $1747 \mathrm{~cm}^{-1}$ (Figure 1b2), which corresponds to the stretching vibrations of carbonyl groups $(\mathrm{C}=\mathrm{O})$ [54]. In the case of OGP, an increase of peak intensities at 1149 and $1077 \mathrm{~cm}^{-1}$ compared to the control could be due to the intake of small hemicellulose, cellulose and pectin [30] found in GP. Starch structure characterized by the vibrations given at $1022 \mathrm{~cm}^{-1}$ for amorphous and at $1047 \mathrm{~cm}^{-1}$ for short-ordered regions [30] was not significantly affected by the addition of GP. The absorption at $1700-1600 \mathrm{~cm}^{-1}$ was assigned to the Amide I fraction, which could offer information about the secondary structure of proteins [30]. GP addition in wheat flour caused inter- and intramolecular associations compared to the control, which lacked absorbance for these structures. Lower $\alpha$-helix conformations were observed for OGP compared to the control, while $\beta$-turn and antiparallel $\beta$-sheet structures were present in higher proportion. These changes could be possibly related to the protein-polyphenols interactions in the dough matrix, a similar opinion being reported by Ertürk and Meral [56]. Sivam et al. [57] also reported lower $\alpha$-helices and lower intermolecular associations when polyphenols were added to bread. Chen et al. [33] obtained a reduction of $\beta$-turn conformational composition of gluten proteins with grape seeds level increase, while $\beta$-sheet conformations increased. The $\alpha$-helix secondary structures were dominant for both the OGP and control samples, similar results being obtained by Nawrocka et al. [58], who studied the influence of dietary fibers on gluten proteins. Dough rheological properties are directly influenced by protein secondary structure. Our results indicated a stronger and more cohesive dough structure of OGP, which can be related to the formation of protein-fiber complexes. The band at $1670 \mathrm{~cm}^{-1}$ is due to non-hydrogen 
linkages of carbonyl groups in the $\beta$-turn structures of proteins; when carbonyl groups are hydrogen bonded with other compounds, a decrease of their absorption band to smaller wavenumbers should be observed [58]. The results of the present study revealed that in the control sample the protein carbonyl groups were bonded trough non-hydrogen linkages, a fact evidenced by the presence of the $1670 \mathrm{~cm}^{-1}$ band, while in OGP the carbonyl groups would have formed hydrogen bonds with fibers or other GP components, a fact suggested by the shift to the left of the absorption band. This band shift could possibly be attributed also to the presence of polysaccharides such as pectin from GP [58]. On the other hand, the appearance of the absorption band at $1661 \mathrm{~cm}^{-1}$ in the OGP sample (Figure 1b2) could be related to the development of intramolecular and intermolecular hydrogen linkages between glutamine side chains and peptide groups, which was probably due to the influence of the GP fiber-rich ingredient [58]. The band at $1625 \mathrm{~cm}^{-1}$ observed for OGP can be associated with the hydrogen bonding of protein aggregates and/or of polypeptide chains complexed with phenolic compounds [59] from GP, as shown by their chemical composition.

GP raised the protein, lipid, ash and carbohydrate contents of pasta due to their intake of nutrients. Compared to our study, Saad et al. [28] showed that cucumber pomace addition in soft wheat noodles increased the mineral and polyphenols content, but decreased protein and carbohydrates. The addition of GP caused higher radical scavenging activity compared to the control, in agreement with the polyphenols content, which presented a raised value for pasta samples with GP. Gaita et al. [17] also reported higher antioxidant capacity of pasta enriched with grape peels. Cooked pasta RDS significantly decreased $(p<0.01)$ when GP were added, while SDS increased compared to the control. Similar trends of RDS and SDS were reported by Simonato et al. [25] when wheat pasta was fortified with olive pomace, which may be due to the starch content reduction caused by the addition of the fiber-rich ingredient. These results could be related to the starch-polyphenol interactions that may occur during pasta making. It has been demonstrated that polyphenols can reduce starch digestion rates due to their interactions trough hydrophobic forces with amylose and the linear fraction of amylopectin and/or to the inhibition effects on enzymes [49]. On the other hand, fibers from GP could compete with starch granule for water, reducing starch gelatinization, thereby causing starch digestibility limitation [25].

GP incorporation resulted in a compact dough structure in which the proteins embedded the fine particles of fibers and starch grains. Similar results were presented by Tolve et al. [1] for durum wheat pasta with grape pomace. The denser gluten network of pasta with GP is probably due to the intake of protein, cellulose and polysaccharides, which can act as fillers in the gluten matrix, while the polyphenols present in GP may interact with gluten proteins to support the formation of a gluten matrix, similar observations being made by Chen et al. [33] for pasta enriched with $1 \%$ grape seeds. Huang et al. [60] also reported a dense structure of wheat noodles formed of starch granules embedded in a developed fiber matrix. Pasta surface roughness was higher when GP was added. This increase could be possibly due to the difference in the water absorption capacity of the composite flour compared to the control, a difference caused by the presence of fibers from GP [34]. According to the study of Chen et al. [33], the incorporation of more than 3\% grape seeds in wheat noodles induced the appearance of jagged edges and uneven mesh structure of pasta caused by the non-gluten components.

\section{Materials and Methods}

\subsection{Materials}

The research was conducted on 650 white wheat (Triticum aestivum) flour (WWF) type from the 2019 harvest, provided by Dizing S.R.L. (Brusturi, Neamt, Romania). Wheat flour chemical components reported to dry matter were: lipids content of $1.11 \pm 0.03 \%$, protein content of $14.41 \pm 0.21 \%$, carbohydrates $81.26 \pm 0.16 \%$, ash content of $0.60 \pm 0.05 \%$, moisture of $14.01 \pm 0.16 \%$, total polyphenols content of $105.59 \pm 4.42 \mu \mathrm{g} \mathrm{GAE} / \mathrm{g}$. The falling number was $404 \pm 1.73 \mathrm{~s}$, wet gluten content was $29.75 \pm 0.15 \%$, dry gluten was 
$10.04 \pm 0.13 \%$, gluten deformation index was $6.17 \pm 0.29 \mathrm{~mm}$ and the water absorption capacity was $59.54 \pm 0.31 \%$. Grape pomace from the Fetească Regală variety was provided by Iași Research and Development Center for Viticulture and Vinification and was dried in a convection oven at $50{ }^{\circ} \mathrm{C}$ for $18 \mathrm{~h}$. Grape peels were manually separated, ground and sieved to obtain the particle size of $<180 \mu \mathrm{m}$. Grape peels contained $2.50 \pm 0.19 \%$ lipids, $9.85 \pm 0.05 \%$ proteins, $25.25 \pm 0.05 \%$ fibers, $55.73 \pm 0.20 \%$ carbohydrates, $4.47 \pm 0.03 \%$ ash, $8.00 \pm 0.08 \%$ moisture and $1448.69 \pm 15.39 \mu \mathrm{g} \mathrm{GAE} / \mathrm{g}$ polyphenols, $0.40 \pm 0.01 \%$ pectin reported to dry matter $(\mathrm{dm})$ and a water absorption capacity of $271.10 \pm 4.34 \%$. Wheat flour was sieved before mixing in order to achieve a particle size of $<300 \mu \mathrm{m}$. Composite flours were mixed for $15 \mathrm{~min}$ in a Yucebas Y21 machine (Izmir, Turkey).

\subsection{Pasta Processing}

Pasta dough was mixed in a Kitchen Aid mixer (Whirlpool Corporation, Benton Harbor, MI, USA) by adding the amount of water calculated in order to obtain $40 \%$ moisture. Pasta modeling was performed after $15 \mathrm{~min}$ of the dough resting at room temperature, by using a rigatoni mold of the Kitchen Aid machine. Pasta drying was performed in a convection oven, according to the method described by Bergman et al. (1994) as follows: 30 min drying in open air at room temperature, followed by a first step of drying for $60 \mathrm{~min}$ at $40{ }^{\circ} \mathrm{C}$, a second for $120 \mathrm{~min}$ at $80^{\circ} \mathrm{C}$ and a third for $120 \mathrm{~min}$ at $40{ }^{\circ} \mathrm{C}$.

\subsection{Evaluation of GP Effects on WWF and Pasta Quality}

\subsubsection{Flour Pasting Properties}

Flour pasting behavior in terms of peak viscosity $\eta_{\max }(\mathrm{Pa} \cdot \mathrm{s})$ was simulated on a dynamic rheometer Thermo-HAAKE, MARS 40 (Karlsruhe, Germany) with a Peltier temperature controller, by using a cup-cylinder geometry. The method described by Ahmed et al. [61] was adapted as follows: the slurry was kept at $50{ }^{\circ} \mathrm{C}$ for $60 \mathrm{~s}$, followed by a heating at $95{ }^{\circ} \mathrm{C}$ for $222 \mathrm{~s}$, keeping at $95^{\circ} \mathrm{C}$ for $210 \mathrm{~s}$, cooling at $50{ }^{\circ} \mathrm{C}$ for $228 \mathrm{~s}$ and keeping at $50{ }^{\circ} \mathrm{C}$ for $120 \mathrm{~s}$.

\subsubsection{Fundamental Rheological Behavior}

Laminated dough samples were rested for $30 \mathrm{~min}$ for internal strain removal and tested for linear viscoelastic region (LVR) by using a Thermo-HAAKE, MARS 40 (Karlsruhe, Germany). A frequency sweep test was performed for the determination of the complex modulus $\mathrm{G}^{*}(\mathrm{~Pa})$. For this purpose, the sample was placed between the parallel plates at a $3 \mathrm{~mm}$ gap and a vaseline layer was applied on the exposed edges for moisture loss prevention. The frequency was varied from 0.1 to $20 \mathrm{~Hz}$, at a strain of $15 \mathrm{~Pa}$ that was in the LVR.

\subsubsection{Dough Texture}

For dough cohesiveness $(\mathrm{Co})$ determination, a texture analysis was performed by using a Perten TVT-6700 texturometer (Perten Instruments, Hägersten, Sweden). A double compression was applied to dough balls of $50 \mathrm{~g}$ weight, at $50 \%$ height, a speed of $5.0 \mathrm{~mm} / \mathrm{s}$ and a trigger force of $20 \mathrm{~g}$ [62].

\subsubsection{Dry Pasta Color}

Pasta chroma $C^{*}$ Equation (11) of the CIE Lab system was determined by reflectance by using a Konica Minolta CR-400 (Tokyo, Japonia) colorimeter.

$$
C^{*}=\sqrt{a^{* 2}+b^{* 2}}
$$

where $\mathrm{C}^{*}$ —chroma, $\mathrm{a}^{*}$-red or green nuance, $\mathrm{b}^{*}$ - yellow or blue nuance. 


\subsubsection{Pasta Fracturability}

Pasta fracturability as the maximum force $\mathrm{F}(\mathrm{g})$ required to break a dry pasta piece was determined with a Perten TVT-6700 texturometer (Perten Instruments, Sweden). An aluminum break rig set adjusted to $13 \mathrm{~mm}$ width was used, the test speed being set to $3 \mathrm{~mm} / \mathrm{s}$ and the trigger force to $50 \mathrm{~g}$ [62].

\subsubsection{Total Polyphenolics Content}

The extracts were prepared according to the method described by Melilli et al. [63]. An amount of $2 \mathrm{~g}$ of grinded uncooked dry pasta was extracted with $20 \mathrm{~mL}$ of methanol $80 \%(v / v)$ in a sonication bath at $37^{\circ} \mathrm{C}$ and $45 \mathrm{~Hz}$ for $40 \mathrm{~min}$, and then the mix was filtered. Total polyphenols content (TPC) ( $\mu \mathrm{g}$ GAE/g dm) of dry pasta was evaluated by using the Folin-Ciocalteu method [64]. The extract was diluted in a ratio of 1:4 with distillated water and mixed with Folin-Ciocalteu reagent $(1 \mathrm{~N})$ and sodium carbonate $20 \%(v / v)$ and left to rest in darkness for $40 \mathrm{~min}$. The absorbance was read at $725 \mathrm{~nm}$ on an UV-VIS-NIR Shimadzu 3600 (Tokyo, Japan) spectrophotometer. TPC was calculated from a calibration curve $\left(R^{2}=0.99\right)$ made with gallic acid (GAE).

\subsubsection{Total Dietary Fiber Content}

For dietary fiber content TDF (\% dm) estimation, a FOSS 6500 NIR (FOSS NIRSystems, Silver Springs, FL, USA) infrared spectrometer was used. Uncooked dry pasta samples were ground before the analysis and the spectra were collected at room temperature. For calibration, off the shelf INGOT commercial calibrations (AUNIR, Towcester, UK) were used. Standard materials provided by AUNIR were used for bias corrections [65].

\subsubsection{Pasta Cooking Behavior}

The loss of solids CL (\%) during pasta cooking was determined gravimetrically by evaporation of the water that resulted after boiling $10 \mathrm{~g}$ of pasta in $200 \mathrm{~mL}$ of water for the optimum cooking time previously established [66].

\subsubsection{Boiled Pasta Texture}

Pasta chewiness $\mathrm{Ch}(\mathrm{J})$ was determined by double cycle compression on one piece of pasta by using a Perten TVT-6700 device (Perten Instruments, Sweden) equipped with a $35 \mathrm{~mm}$ cylinder probe, at $50 \%$ of the sample height, a test speed of $5.0 \mathrm{~mm} / \mathrm{s}$ and a trigger force of $20 \mathrm{~g}$ [62].

4.3.10. Rapid Digestible Starch (RDS), Slowly Digestible Starch (SDS) and Resistant Starch (RS) Contents

The international AOAC 2017.16 method was used for RDS, SDS and RS determination from boiled pasta, by using Megazyme kit. After $20 \mathrm{~min}$ (for RDS), $120 \mathrm{~min}$ (for SDS) or $240 \mathrm{~min}$ (for RS) of sample digestion with $\alpha$-amylase and amyloglucosidase the reaction was stopped and the mix was digested again with amyloglucosidase. The resulting glucose was determined by using GOPOD reagent and reading of the absorbance at $510 \mathrm{~nm}$. The results were reported as percent to dry matter.

\subsection{Optimization of Grape Peels Level and Models Validation}

GP level optimization was performed by using the trial version of Design Expert software (Stat-Ease, Inc., Minneapolis, USA). For this purpose, the multiple response optimization and the desirability function were used and the goals were selected as follows: $\mathrm{G}^{*}, \mathrm{Co}, \mathrm{C}^{*}, \mathrm{~F}, \mathrm{TPC}, \mathrm{TDF}$ and RS were maximized, $\mathrm{CL}$ and $\mathrm{Ch}$ were minimized, and $\eta_{\max }{ }^{*}$ was kept in range. The experimental design matrix containing mean values of three replications of the responses is presented in Table 4. 
Table 4. The effects of GP on the responses used in the experimental design.

\begin{tabular}{|c|c|c|c|c|c|c|c|c|c|c|}
\hline $\begin{array}{l}\text { GP } \\
(\%)\end{array}$ & $\begin{array}{r}\eta_{\max } \\
\mathbf{( P a} \cdot \mathbf{s})\end{array}$ & $\begin{array}{l}\mathrm{G}^{*} \\
(\mathrm{~Pa})\end{array}$ & $\begin{array}{c}\text { Co } \\
\text { (adim.) }\end{array}$ & $\begin{array}{c}\mathrm{C}^{*} \\
\text { (adim.) }\end{array}$ & $\begin{array}{l}F \\
(g)\end{array}$ & $\begin{array}{l}\text { CL } \\
(\%)\end{array}$ & $\begin{array}{l}\mathrm{Ch} \\
\text { (J) }\end{array}$ & $\begin{array}{c}\text { RS } \\
(\% \mathrm{dm})\end{array}$ & $\begin{array}{c}\text { TPC } \\
(\mu \mathrm{g} \mathrm{GAE} / \mathrm{g} \mathrm{dm})\end{array}$ & $\begin{array}{c}\text { TDF } \\
(\% \mathrm{dm})\end{array}$ \\
\hline 1.00 & $0.56 \pm 0.03$ & $82,936.67 \pm 4914.90$ & $0.39 \pm 0.01$ & $21.46 \pm 0.63$ & $4181.00 \pm 103.00$ & $4.55 \pm 0.30$ & $4034.97 \pm 9.10$ & $3.20 \pm 0.08$ & $102.00 \pm 7.11$ & $0.02 \pm 0.01$ \\
\hline 2.00 & $0.62 \pm 0.05$ & $90,176.67 \pm 7961.22$ & $0.39 \pm 0.01$ & $20.94 \pm 0.47$ & $4357.00 \pm 199.02$ & $5.43 \pm 0.18$ & $3975.14 \pm 168.70$ & $4.10 \pm 0.05$ & $118.72 \pm 2.76$ & $0.35 \pm 0.05$ \\
\hline 4.00 & $0.81 \pm 0.04$ & $99,103.33 \pm 7081.74$ & $0.41 \pm 0.01$ & $19.65 \pm 0.26$ & $4998.33 \pm 15.50$ & $6.09 \pm 0.31$ & $3621.45 \pm 100.87$ & $4.57 \pm 0.01$ & $129.12 \pm 2.00$ & $1.05 \pm 0.05$ \\
\hline 5.00 & $0.83 \pm 0.16$ & $122,600.00 \pm 6080.60$ & $0.42 \pm 0.01$ & $18.78 \pm 0.23$ & $5685.67 \pm 54.78$ & $7.28 \pm 0.36$ & $3589.50 \pm 119.78$ & $4.67 \pm 0.04$ & $149.27 \pm 2.02$ & $1.30 \pm 0.00$ \\
\hline 6.00 & $0.87 \pm 0.07$ & $131,893.33 \pm 8144.26$ & $0.43 \pm 0.01$ & $18.54 \pm 0.25$ & $5961.00 \pm 17.00$ & $7.99 \pm 0.14$ & $3478.03 \pm 102.51$ & $4.88 \pm 0.16$ & $157.02 \pm 4.38$ & $1.50 \pm 0.00$ \\
\hline
\end{tabular}

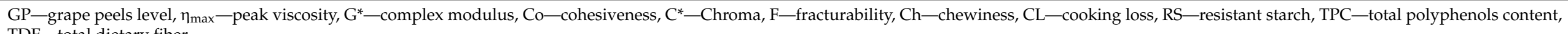

TDF- total dietary fiber. 
For model validation, pasta was made using the optimal level of GP obtained and the response values were checked. The real values of the optimum sample characteristics were compared to the control made of untreated wheat flour. For the evaluation of differences among the predicted and the experimental results of the optimal solution, and among the optimal and control sample, $t$ tests for two samples $(p<0.05)$ were performed.

\subsection{Determination of Control and Optimal Product Properties}

\subsubsection{Chemical Composition and Antioxidant Activity}

The chemical composition was determined according to the Romanian and International standard methods and the results are reported to dry matter: moisture (SR EN ISO 712/2010), ash (SR ISO 2171/2002), protein (SR EN ISO 20483/2007) and lipids (SR 91/2007). TDF was determined by NIR (as described in Section 4.3.6) and the carbohydrates were calculated by difference.

The radical scavenging activity (\%) was evaluated by using 2, 2-di (4-tert-octylphenyl)1-picrylhydrazyl (DPPH). The extract prepared as described in Section 4.3.5 (0.5 mL) was diluted with methanol $80 \%(0.5 \mathrm{~mL})$ and mixed with $5 \mathrm{~mL}$ of DPPH. After resting $30 \mathrm{~min}$ in the darkness the absorbance was read at $517 \mathrm{~nm}$ on an UV-VIS-NIR Shimadzu 3600 (Tokyo, Japan) spectrophotometer [67].

\subsubsection{ATR-FT-IR Analysis of Flour}

FT-IR spectra of the flours were collected in triplicate in the range of 650 to $4000 \mathrm{~cm}^{-1}$ by using a Thermo Scientific Nicolet iS20 (Waltham, MA, USA) spectrometer, at a resolution of $8 \mathrm{~cm}^{-1}$ by 64 scans. The fractions of amide I (1835-1585 $\left.\mathrm{cm}^{-1}\right)$, polyphenols (1516-1747 $\left.\mathrm{cm}^{-1}\right)$ and starch $\left(800-1300 \mathrm{~cm}^{-1}\right)$ were identified, the data being processed with OMNIC software. The starch, polyphenols and protein structures were assessed according to previous studies [31,68-70]. Fourier deconvolution was applied in order to characterize starch and protein structures.

\subsubsection{Microstructure}

Electronic scanning microscopy was employed for flour microstructure evaluation with a VEGA II LSH scanning electronic microscope (Tescan, Brno, Czech Republic). The acceleration tension was $30 \mathrm{kV}$ and the magnification $1000 \times$, the samples being fixed with adhesive carbon bands.

Pasta surface structure analysis was performed on a Mahr CWM100 microscope (Gottingen, Germany). The data collected were processed with Mountain Map trial version software (Digital Surf, Besançon, France).

\subsection{Statistical Analysis}

All of the analyses in the present study were performed in triplicate. XLSTAT for Excel 2021 version (Addinsoft, New York, USA) was used for statistical analysis of the data. In order to evaluate the significant differences $(p<0.05)$ among samples the $t$-test was used.

For the assessment of GP addition effects on WWF and pasta quality, mathematical modeling of the results was carried out by using the trial version of Design Expert software (Stat-Ease, Inc., Minneapolis, USA), by applying response surface methodology (RSM). The effect of GP level factor on the responses ( $\eta_{\max }, \mathrm{G}^{*}, \mathrm{Co}, \mathrm{C}^{*}, \mathrm{Ch}, \mathrm{F}, \mathrm{CL}, \mathrm{TPC}, \mathrm{TDF}$ and RS) was observed by using a D-optimal design with one factor varied at six levels $(1,2,3,4,5$, $6 \%$ ) and three replications. The model's fitting was evaluated through a sequential Fisher test, coefficients of determination $\left(R^{2}\right)$ and adjusted coefficient of determination $\left(\right.$ Adj.- $\left.R^{2}\right)$, at a $95 \%$ confidence level. The most suitable model was selected according to the highest Adj.- $R^{2}$ value. 


\section{Conclusions}

The addition of grape peels increased the amounts of nutrients in wheat pasta, especially fibers, resistant starch and polyphenols, which are compounds with many health benefits. The optimal quantity of grape peels that can be added to wheat flour was found to be $4.62 \%$. Dough cohesiveness, dry pasta fracturability and cooked pasta chewiness were enhanced compared to the control, while the cooking losses were within acceptable limits $(<12 \%)$. Starch digestibility of pasta was positively influenced by grape peels, higher resistant starch, slowly digestible starch and lower rapid digestible starch being obtained. Interactions between wheat flour and grape peels were shown trough FT-IR analysis, significant changes of protein structures being observed. A compact microstructure of pasta was noticed at $4.62 \%$ addition of small particle sizes $(<180 \mu \mathrm{m})$. Thus, this study can be helpful for both processors and consumers, underlying the opportunity to enhance the nutritional value of wheat pasta by incorporating grape peels, with benefits for human health and environmental waste management. This research was performed on a laboratory scale, and thus more investigations at the industrial level are needed.

Supplementary Materials: The following are available online at https:/ / www.mdpi.com/article/10

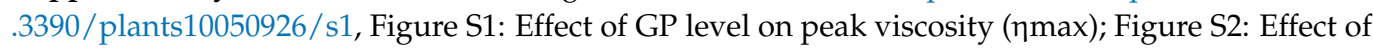
GP level on dough: a. complex modulus $\left(\mathrm{G}^{*}\right)$, b. cohesiveness (Co); Figure S3: Effect of GP level on dry pasta: a. chroma $\left(C^{*}\right)$, b. fracturability $(F)$; Figure S4: Effect of GP level on pasta: a. cooking loss (CL), b. chewiness (Ch); Figure S5: Effect of GP level on pasta: a. resistant starch content (RS), b. total polyphenols content (TPC), c. total dietary fiber (TDF).

Author Contributions: The authors contributed equally to this research. All of the authors examined and approved the contents of the article. All authors have read and agreed to the published version of the manuscript.

Funding: This work was funded by Stefan cel Mare University of Suceava, Romania.

Institutional Review Board Statement: Not applicable.

Informed Consent Statement: Not applicable.

Data Availability Statement: Not applicable.

Conflicts of Interest: The authors declare no conflict of interest.

\section{References}

1. Tolve, R.; Pasini, G.; Vignale, F.; Favati, F.; Simonato, B. Effect of Grape Pomace Addition on the Technological, Sensory, and Nutritional Properties of Durum Wheat Pasta. Foods 2020, 9, 354. [CrossRef] [PubMed]

2. Hogervorst, J.C.; Miljić, U.; Puškaš, V. Extraction of Bioactive Compounds from Grape Processing By-Products. In Handbook of Grape Processing By-Products; Elsevier BV: Amsterdam, The Netherlands, 2017; pp. 105-135.

3. Iuga, M.; Mironeasa, S. Potential of grape byproducts as functional ingredients in baked goods and pasta. Compr. Rev. Food Sci. Food Saf. 2020, 19, 2473-2505. [CrossRef] [PubMed]

4. Spinelli, S.; Padalino, L.; Costa, C.; del Nobile, M.A.; Conte, A. Food by-products to fortified pasta: A new approach for optimization. J. Clean. Prod. 2019, 215, 985-991. [CrossRef]

5. Sant'Anna, V.; Christiano, F.D.P.; Marczak, L.D.F.; Tessaro, I.C.; Thys, R.C.S. The effect of the incorporation of grape marc powder in fettuccini pasta properties. LWT 2014, 58, 497-501. [CrossRef]

6. Minarovičová, L.; Karovičová, J.; Kohajdová, Z.; Kuchtová, V. The Chemical Composition of Grape Fibre. Potravin. Slovak J. Food Sci. 2015, 9, 53-57. [CrossRef]

7. Iuga, M.; Ropciuc, S.; Mironeasa, S. Antioxidant Activity and Total Phenolic Content of Grape Seeds and Peels from Romanian Varieties. Food Environ. Saf. J. 2017, 16, 276-282.

8. Troilo, M.; Difonzo, G.; Paradiso, V.; Summo, C.; Caponio, F. Bioactive Compounds from Vine Shoots, Grape Stalks, and Wine Lees: Their Potential Use in Agro-Food Chains. Foods 2021, 10, 342. [CrossRef]

9. Olejar, K.J.; Ricci, A.; Swift, S.; Zujovic, Z.; Gordon, K.C.; Fedrizzi, B.; Versari, A.; Kilmartin, P.A. Characterization of an Antioxidant and Antimicrobial Extract from Cool Climate, White Grape Marc. Antioxidants 2019, 8, 232. [CrossRef]

10. Deng, Q.; Penner, M.H.; Zhao, Y. Chemical composition of dietary fiber and polyphenols of five different varieties of wine grape pomace skins. Food Res. Int. 2011, 44, 2712-2720. [CrossRef]

11. Meini, M.-R.; Cabezudo, I.; Boschetti, C.E.; Romanini, D. Recovery of phenolic antioxidants from Syrah grape pomace through the optimization of an enzymatic extraction process. Food Chem. 2019, 283, 257-264. [CrossRef] [PubMed] 
12. Oliveira, D.A.; Salvador, A.A.; Smânia, A.; Smânia, E.F.; Maraschin, M.; Ferreira, S.R. Antimicrobial activity and composition profile of grape (Vitis vinifera) pomace extracts obtained by supercritical fluids. J. Biotechnol. 2013, 164, 423-432. [CrossRef]

13. Zhu, F.; Du, B.; Zheng, L.; Li, J. Advance on the bioactivity and potential applications of dietary fibre from grape pomace. Food Chem. 2015, 186, 207-212. [CrossRef] [PubMed]

14. Mironeasa, S. Valorisation of Secondary Products from Wine Making; Publishing House Performantica: Iasi, Romania, 2017.

15. Bender, A.B.B.; Speroni, C.S.; Salvador, P.R.; Loureiro, B.B.; Lovatto, N.M.; Goulart, F.R.; Lovatto, M.T.; Miranda, M.Z.; Silva, L.P.; Penna, N.G. Grape Pomace Skins and the Effects of Its Inclusion in the Technological Properties of Muffins. J. Culin. Sci. Technol. 2017, 15, 143-157. [CrossRef]

16. Mironeasa, S.; Iuga, M.; Zaharia, D.; Mironeasa, C. Optimization of grape peels particle size and flour substitution in white wheat flour dough. Sci. Study Res. Chem. Chem. Eng. Biotechnol. Food Ind. 2019, 20, 29-42.

17. Gaita, C.; Alexa, E.; Moigradean, D.; Conforti, F.; Poiana, M.-A. Designing of high value-added pasta formulas by incorporation of grape pomace skins. Rom. Biotechnol. Lett. 2020, 25, 1607-1614. [CrossRef]

18. Iuga, M.; Mironeasa, C.; Mironeasa, S. Oscillatory Rheology and Creep-Recovery Behaviour of Grape Seed-Wheat Flour Dough: Effect of Grape Seed Particle Size, Variety and Addition Level. Bull. Univ. Agric. Sci. Veter. Med. Cluj Napoca. Food Sci. Technol. 2019, 76, 40-51. [CrossRef]

19. Simonato, B.; Tolve, R.; Rainero, G.; Rizzi, C.; Sega, D.; Rocchetti, G.; Lucini, L.; Giuberti, G. Technological, nutritional, and sensory properties of durum wheat fresh pasta fortified with Moringa oleifera L. leaf powder. J. Sci. Food Agric. 2021, 101, 1920-1925. [CrossRef]

20. Sykut-Domańska, E.; Zarzycki, P.; Sobota, A.; Teterycz, D.; Wirkijowska, A.; Blicharz-Kania, A.; Andrejko, D.; Mazurkiewicz, J. The potential use of by-products from coconut industry for production of pasta. J. Food Process. Preserv. 2020, 44, 1-9. [CrossRef]

21. Sobota, A.; Wirkijowska, A.; Zarzycki, P. Application of vegetable concentrates and powders in coloured pasta production. Int. J. Food Sci. Technol. 2020, 55, 2677-2687. [CrossRef]

22. Xu, J.; Bock, J.E.; Stone, D. Quality and textural analysis of noodles enriched with apple pomace. J. Food Process. Preserv. 2020, 44, 44. [CrossRef]

23. Michalak-Majewska, M.; Teterycz, D.; Muszyński, S.; Radzki, W.; Sykut-Domańska, E. Influence of onion skin powder on nutritional and quality attributes of wheat pasta. PLoS ONE 2020, 15, e0227942. [CrossRef] [PubMed]

24. Zarzycki, P.; Teterycz, D.; Wirkijowska, A.; Kozłowicz, K.; Stasiak, D.M. Use of moldavian dragonhead seeds residue for pasta production. LWT 2021, 143, 111099. [CrossRef]

25. Simonato, B.; Trevisan, S.; Tolve, R.; Favati, F.; Pasini, G. Pasta fortification with olive pomace: Effects on the technological characteristics and nutritional properties. LWT 2019, 114, 108368. [CrossRef]

26. Giuberti, G.; Rocchetti, G.; Lucini, L. Interactions between phenolic compounds, amylolytic enzymes and starch: An updated overview. Curr. Opin. Food Sci. 2020, 31, 102-113. [CrossRef]

27. Wang, Y.; Chao, C.; Huang, H.; Wang, S.; Wang, S.; Wang, S.; Copeland, L. Revisiting Mechanisms Underlying Digestion of Starches. J. Agric. Food Chem. 2019, 67, 8212-8226. [CrossRef]

28. Saad, A.M.; El-Saadony, M.T.; Mohamed, A.S.; Ahmed, A.I.; Sitohy, M.Z. Impact of cucumber pomace fortification on the nutritional, sensorial and technological quality of soft wheat flour-based noodles. Int. J. Food Sci. Technol. 2021, $2021,1-14$. [CrossRef]

29. Tuoc, T.; Glasgow, S. On the texture profile analysis test. In Proceedings of the Chemeca 2012: Quality of life through chemical engineering, Wellington, New Zealand, 23-26 September 2012; pp. 749-760.

30. González, M.; Vernon-Carter, E.; Alvarez-Ramirez, J.; Carrera-Tarela, Y. Effects of dry heat treatment temperature on the structure of wheat flour and starch in vitro digestibility of bread. Int. J. Biol. Macromol. 2021, 166, 1439-1447. [CrossRef]

31. Marti, A.; Bock, J.E.; Pagani, M.A.; Ismail, B.; Seetharaman, K. Structural characterization of proteins in wheat flour doughs enriched with intermediate wheatgrass (Thinopyrum intermedium) flour. Food Chem. 2016, 194, 994-1002. [CrossRef] [PubMed]

32. Gao, X.; Tong, J.; Guo, L.; Yu, L.; Li, S.; Yang, B.; Wang, L.; Liu, Y.; Li, F.; Guo, J.; et al. Influence of gluten and starch granules interactions on dough mixing properties in wheat (Triticum aestivum L.). Food Hydrocoll. 2020, 106, 105885. [CrossRef]

33. Chen, S.-X.; Ni, Z.-J.; Thakur, K.; Wang, S.; Zhang, J.-G.; Shang, Y.-F.; Wei, Z.-J. Effect of grape seed power on the structural and physicochemical properties of wheat gluten in noodle preparation system. Food Chem. 2021, 355, 129500. [CrossRef]

34. Mironeasa, S.; Iuga, M.; Zaharia, D.; Mironeasa, C. Rheological Analysis of Wheat Flour Dough as Influenced by Grape Peels of Different Particle Sizes and Addition Levels. Food Bioprocess Technol. 2018, 12, 228-245. [CrossRef]

35. Gull, A.; Prasad, K.; Kumar, P. Nutritional, antioxidant, microstructural and pasting properties of functional pasta. J. Saudi Soc. Agric. Sci. 2018, 17, 147-153. [CrossRef]

36. Masoodi, F.A.; Chauhan, G.S.; Tyagi, S.M.; Kumbhar, B.; Kaur, H. Effect of Apple Pomace Incorporation on Rheological Characteristics of Wheat Flour. Int. J. Food Prop. 2001, 4, 215-223. [CrossRef]

37. Samohvalova, O.; Grevtseva, N.; Brykova, T.; Grigorenko, A. The effect of grape seed powder on the quality of butter biscuits. East. Eur. J. Enterp. Technol. 2016, 3, 61. [CrossRef]

38. Kohajdová, Z.; Karovičová, J.; Magala, M.; Kuchtová, V. Effect of apple pomace powder addition on farinographic properties of wheat dough and biscuits quality. Chem. Pap. 2014, 68, 1059-1065. [CrossRef]

39. Chevallier, S.; Colonna, P.; Buléon, A.; della Valle, G. Physicochemical Behaviors of Sugars, Lipids, and Gluten in Short Dough and Biscuit. J. Agric. Food Chem. 2000, 48, 1322-1326. [CrossRef] [PubMed] 
40. Smith, I.N.; Yu, J. Nutritional and Sensory Quality of Bread Containing Different Quantities of Grape Pomace from Different Grape Cultivars. EC Nutr. 2015, 2, 291-301.

41. Aksoylu, Z.; Çağindi, Ö.; Köse, E. Effects of Blueberry, Grape Seed Powder and Poppy Seed Incorporation on Physicochemical and Sensory Properties of Biscuit. J. Food Qual. 2015, 38, 164-174. [CrossRef]

42. Mehta, R.S. Addressing texture challenges in baked goods with fiber. Food Texture Des. Optim. 2014, 245-280. [CrossRef]

43. Tkacz, K.; Wojdyło, A.; Nowicka, P.; Turkiewicz, I.; Golis, T. Characterization in vitro potency of biological active fractions of seeds, skins and flesh from selected Vitis vinifera L. cultivars and interspecific hybrids. J. Funct. Foods 2019, 56, 353-363. [CrossRef]

44. Sun, K.-N.; Liao, A.-M.; Zhang, F.; Thakur, K.; Zhang, J.-G.; Huang, J.-H.; Wei, Z.-J. Microstructural, Textural, Sensory Properties and Quality of Wheat-Yam Composite Flour Noodles. Foods 2019, 8, 519. [CrossRef] [PubMed]

45. Bustos, M.C.; Paesani, C.; Quiroga, F.; León, A.E. Technological and sensorial quality of berry-enriched pasta. Cereal Chem. J. 2019, 96, 967-976. [CrossRef]

46. Camelo-Méndez, G.A.; Agama-Acevedo, E.; Tovar, J.; Bello-Pérez, L.A. Functional study of raw and cooked blue maize flour: Starch digestibility, total phenolic content and antioxidant activity. J. Cereal Sci. 2017, 76, 179-185. [CrossRef]

47. Rocchetti, G.; Giuberti, G.; Busconi, M.; Marocco, A.; Trevisan, M.; Lucini, L. Pigmented sorghum polyphenols as potential inhibitors of starch digestibility: An in vitro study combining starch digestion and untargeted metabolomics. Food Chem. 2020, 312, 126077. [CrossRef] [PubMed]

48. Chi, C.; Li, X.; Zhang, Y.; Chen, L.; Li, L.; Wang, Z. Digestibility and supramolecular structural changes of maize starch by non-covalent interactions with gallic acid. Food Funct. 2017, 8, 720-730. [CrossRef]

49. Sun, L.; Miao, M. Dietary polyphenols modulate starch digestion and glycaemic level: A review. Crit. Rev. Food Sci. Nutr. 2020, 60, 541-555. [CrossRef]

50. Gomes, T.M.; Toaldo, I.M.; Haas, I.C.D.S.; Burin, V.M.; Caliari, V.; Luna, A.S.; de Gois, J.S.; Bordignon-Luiz, M.T. Differential contribution of grape peel, pulp, and seed to bioaccessibility of micronutrients and major polyphenolic compounds of red and white grapes through simulated human digestion. J. Funct. Foods 2019, 52, 699-708. [CrossRef]

51. Acun, S.; Gül, H. Effects of grape pomace and grape seed flours on cookie quality. Qual. Assur. Saf. Crop. Foods 2014, 6, 81-88. [CrossRef]

52. Wyrwisz, M.K.J. The Application of Dietary Fiber in Bread Products. J. Food Process. Technol. 2015, 6, 6. [CrossRef]

53. Balli, D.; Cecchi, L.; Innocenti, M.; Bellumori, M.; Mulinacci, N. Food by-products valorisation: Grape pomace and olive pomace (pâté) as sources of phenolic compounds and fiber for enrichment of tagliatelle pasta. Food Chem. 2021, 355, 129642. [CrossRef]

54. Zhao, X.; Zhu, H.; Zhang, G.; Tang, W. Effect of superfine grinding on the physicochemical properties and antioxidant activity of red grape pomace powders. Powder Technol. 2015, 286, 838-844. [CrossRef]

55. Silva, S.D.; Feliciano, R.P.; Boas, L.V.; Bronze, M.R. Application of FTIR-ATR to Moscatel dessert wines for prediction of total phenolic and flavonoid contents and antioxidant capacity. Food Chem. 2014, 150, 489-493. [CrossRef] [PubMed]

56. Ertürk, B.; Meral, R. The impact of stabilization on functional, molecular and thermal properties of rice bran. J. Cereal Sci. 2019, 88, 71-78. [CrossRef]

57. Sivam, A.; Sun-Waterhouse, D.; Perera, C.; Waterhouse, G. Exploring the interactions between blackcurrant polyphenols, pectin and wheat biopolymers in model breads; a FTIR and HPLC investigation. Food Chem. 2012, 131, 802-810. [CrossRef]

58. Nawrocka, A.; Szymanskachargot, M.; Miś, A.; Ptaszyńska, A.A.; Kowalski, R.; Waśko, P.; Gruszecki, W.I. Influence of dietary fibre on gluten proteins structure-A study on model flour with application of FT-Raman spectroscopy. J. Raman Spectrosc. 2015, 46, 309-316. [CrossRef]

59. Nawrocka, A.; Miś, A.; Niewiadomski, Z. Dehydration of gluten matrix as a result of dietary fibre addition-A study on model flour with application of FT-IR spectroscopy. J. Cereal Sci. 2017, 74, 86-94. [CrossRef]

60. Huang, D.-W.; Chan, Y.-J.; Huang, Y.-C.; Chang, Y.-J.; Tsai, J.-C.; Mulio, A.; Wu, Z.-R.; Hou, Y.-W.; Lu, W.-C.; Li, P.-H. Quality Evaluation, Storage Stability, and Sensory Characteristics of Wheat Noodles Incorporated with Isomaltodextrin. Plants 2021, 10, 578. [CrossRef]

61. Ahmed, J.; Ramaswamy, H.S.; Ayad, A.; Alli, I. Thermal and dynamic rheology of insoluble starch from basmati rice. Food Hydrocoll. 2008, 22, 278-287. [CrossRef]

62. Ungureanu-Iuga, M.; Dimian, M.; Mironeasa, S. Development and quality evaluation of gluten-free pasta with grape peels and whey powders. LWT 2020, 130, 109714. [CrossRef]

63. Melilli, M.G.; Pagliaro, A.; Scandurra, S.; Gentile, C.; di Stefano, V. Omega-3 rich foods: Durum wheat spaghetti fortified with Portulaca oleracea. Food Biosci. 2020, 37, 100730. [CrossRef]

64. FAO/IAEA. Quantification of Tannins in Tree Foliage. A Laboratory Manual For the FAO/IAEA Coordinated Research Project on Use of Nuclear and Related Techniques to Develop Simple Tannin Assays for Predicting and Improving the Safety and Efficiency of Feeding Rumina; IAEA: Vienna, Austria, 2000.

65. Haughey, S.A.; Chevallier, O.P.; McVey, C.; Elliott, C.T. Laboratory investigations into the cause of multiple serious and fatal food poisoning incidents in Uganda during 2019. Food Control. 2021, 121, 107648. [CrossRef]

66. Giménez, M.; González, R.; Wagner, J.; Torres, R.; Lobo, M.; Samman, N. Effect of extrusion conditions on physicochemical and sensorial properties of corn-broad beans (Vicia faba) spaghetti type pasta. Food Chem. 2013, 136, 538-545. [CrossRef] [PubMed]

67. Bajerska, J.; Mildner-Szkudlarz, S.; Górnaś, P.; Seglina, D. The effects of muffins enriched with sour cherry pomace on acceptability, glycemic response, satiety and energy intake: A randomized crossover trial. J. Sci. Food Agric. 2015, 96, 2486-2493. [CrossRef] 
68. Chavez-Murillo, C.E.; Orona-Padilla, J.L.; Millan, J.D.L.R. Physicochemical, functional properties and ATR-FTIR digestion analysis of thermally treated starches isolated from black and bayo beans. Starch Stärke 2019, 71, 1-25. [CrossRef]

69. Arslan, F.N.; Akin, G.; Elmas, Ş.N.K.; Üner, B.; Yilmaz, I.; Janssen, H.-G.; Kenar, A. FT-IR spectroscopy with chemometrics for rapid detection of wheat flour adulteration with barley flour. J. Consum. Prot. Food Saf. 2020, 15, 245-261. [CrossRef]

70. Lucarini, M.; Durazzo, A.; Kiefer, J.; Santini, A.; Lombardi-Boccia, G.; Souto, E.; Romani, A.; Lampe, A.; Nicoli, S.F.; Gabrielli, P.; et al. Grape Seeds: Chromatographic Profile of Fatty Acids and Phenolic Compounds and Qualitative Analysis by FTIR-ATR Spectroscopy. Foods 2019, 9, 10. [CrossRef] 